\title{
Current ECG interpretation guide- lines in the screening of athletes
}

\author{
Gemma Parry-Williams, Sanjay Sharma \\ Cardiology Clinical and Academic group, St George's University of London, United Kingdom
}

\section{Summary}

Sudden cardiac death is rare, however the lives of some young athletes are lost prematurely due to cardiovascular dieseases that are detectable during life. It is on this premise that the European Society of Cardiology endorses cardiovascular screening of young athletes using the 12 lead ECG. This review will describe the spectrum of normal ECG patterns in athletes. the impact of demographic factors and sporting intensity on these patterns and define the abnormal ECG findings that warrant further investigation.

Key words: athlete's heart; electrocardiogram; international recommendations; sudden cardiac death

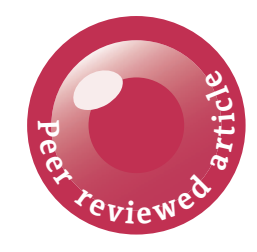

'The athlete's heart' is the term used to describe the physiological adaptations that occur in cardiac structure and function as a result of engaging in intensive physical exercise for 4-8 hours per week. These adaptations manifest in a constellation of changes on the electrocardiogram (ECG) and vary according to demographics such as age, sex and ethnicity, as well as the type of sport and intensity of training [1]. Some of these athletic changes overlap with those seen in inherited cardiac conditions such as cardiomyopathies and channelopathies, which are amongst the leading causes of sudden cardiac death (SCD) during sporting participation [2]. A significant proportion of these conditions can be detected with the ECG. In 'grey' cases, where the ECG does not enable differentiation between physiology and pathology, further examination including investigations such as cardiac magnetic resonance imaging (MRI), exercise stress testing and retesting after detraining, is required [2]. Erroneous diagnoses have serious implications and can result in unfair disqualification from sport or false reassurance. Hence a good working knowledge of the electrical manifestations of physical training is imperative for all physicians involved in the assessment of young athletes.
This review will discuss the current criteria and definitions of the normal ECG in athletes and also those parameters that should be considered abnormal until comprehensive investigation is able to exclude serious disease.

\section{Normal ECG findings in athletes (tab. 1)}

\section{Bradycardia and conduction anomalies}

The ECG in the trained athlete frequently shows patterns associated with increased vagal tone, including slowing of the sinus node and varying degrees of atrioventricular conduction block, that are proportional to the level of conditioning. Sinus bradycardia as slow as $30 \mathrm{bpm}$ and a PR interval of up to $400 \mathrm{~ms}$ are recognised manifestations that do not require further investigation. Mobitz I second-degree atrioventricular conduction block (Wenckebach) and junctional rhythms are also recognised within the physiological spectrum of athletes [3,4]. Gentle exercise testing is useful to demonstrate chronotropic competence, appropriate shortening of the PR interval and reversion to sinus rhythm in the case of Mobitz type 1 second degree atrioventricular block and junctional rhythms. Unless any of these vagally mediated manifestations are accompanied by symptoms, they do not require any further investigations. In contrast, higher degrees of atrioventricular block including Mobitz II and complete heart block are not considered a physiological finding and should be investigated and treated.

\section{Abbreviations}

ARVC arrhythmogenic right ventricular cardiomyopathy

ERP early repolarisation pattern

ESC European society for Cardiology

ECG electrocardiogram

HCM hypertrophic cardiomyopathy

LBBB left bundle-branch block

MRI magagnetic resonance imaging

SCD sudden cardiac death 
Table 1: Normal ECG findings in athletes (adapted from Sharma et al., 2017, International Recommendations for Electrocardiographic Interpretation in Athletes [2]).

\begin{tabular}{ll}
\hline ECG Feature & Definition \\
\hline Left ventricular hypertrophy & Isolated S wave in V1 + R wave in V5 or V6 $>3.5 \mathrm{mV}$ \\
\hline Right ventricular hypertrophy & Isolated R wave in V1 + S wave in V5 or V6 $>1.1 \mathrm{mV}$ \\
\hline $\begin{array}{l}\text { Incomplete right bundle-branch } \\
\text { block }\end{array}$ & $\begin{array}{l}\text { rSR' pattern in lead V1 and an S wave wider than } \\
\mathrm{R} \text { wave in lead V6 with QRS duration }<120 \mathrm{~ms}\end{array}$ \\
\hline Sinus bradycardia & $\geq 30$ bpm \\
\hline Sinus arrhythmia & Heart rate increase during inspiration \\
\hline Ectopic atrial rhythm & P waves of different morphology to sinus P wave \\
\hline Junctional escape rhythm & QRS narrow and faster than P wave \\
\hline $1^{\circ}$ atrioventricular block & Prolonged PR interval up to 400 ms \\
\hline Mobitz II $2^{\circ}$ atrioventricular block & Progressive prolongation of PR interval with even- \\
& tual non-conducted P wave and absent QRS \\
\hline
\end{tabular}

Voltage criteria for left ventricular hypertrophy Up to half of male athletes will exhibit Sokolow-Lyon voltage criteria for left ventricular hypertrophy. However, this correlates poorly with an increased left ventricular wall thickness [5]. Isolated left ventricular hypertrophy is considered normal in athletes, but when accompanied by ST segment depression or T wave inversion, particularly in the inferior or lateral leads, it is suggestive of pathological left ventricular hypertrophy [6].

\section{Early repolarisation pattern}

The early repolarisation pattern (ERP) is defined as: $J$ point elevation $\geq 0.1 \mathrm{mV}$, ST segment elevation, J waves or slurring of the terminal QRS, in the inferior and/or lateral leads [2]. The ERP is observed in approximately $6 \%$ of the general population and 23 and $44 \%$ of white and black athletes, respectively $[7,8]$. Noted more often at slower heart rates and inducible with training, the ERP is yet to be directly associated with adverse events in athletes. Thus it is considered a normal variant in the absence of a history of unheralded syncope or a family history of premature sudden cardiac death $[9,10]$.

\section{Impact of demographics on the ECG}

The electrocardiographic manifestations of the athlete's heart are influenced by several demographic factors and also the type and intensity of sporting activity.

\section{The 'juvenile' pattern (age $<16$ years)}

Anterior $\mathrm{T}$ wave inversion is relatively common and more extensive in athletes under the age of 16 . T wave inversion extending to V3 or an isolated biphasic Twave in V3 are commonly referred to as the 'juvenile ECG pattern', and are a normal finding in the adoles- cent athlete (age <16) with a prevalence of 4 to $9.5 \%$. T wave inversion beyond V2 in older athletes is less common, particularly in males, $(0.8 \%)$, and persistence of the pattern should trigger investigation $[11,12]$.

\section{The black athlete}

The greater magnitude of left ventricular hypertrophy seen in the black athlete means their ECG findings more frequently fall into the grey area for differentiating physiology and pathology. T wave inversion is detected in up to $25 \%$ of black athletes (fig. 1). The most common pattern is anterior T wave inversion (V1-V4), accompanied by J point elevation and convex ST segment elevation, seen in up to $13 \%$. Current studies reveal that this specific repolarisation pattern is benign and does not require investigation in an asymptomatic athlete [13].

\section{The female athlete}

Females show similar qualitative features to male athletes but to a lesser extent [14]. An exception to this is anterior $\mathrm{T}$ wave inversion in leads $\mathrm{V} 1$ and $\mathrm{V} 2$, which is more common in females ( $4.3 \%$ females vs $1.4 \%$ males; $\mathrm{p}<0.0001)[16]$.

\section{Endurance athletes}

Endurance athletes show the most profound ECG features of cardiac adaptation. Sinus bradycardia, Mobitz type 1 second-degree atrioventricular block, increased voltages and the ERP are most common in this group. In our experience, $T$ wave inversion in the right precordial leads (up to V3), is present in a small proportion of endurance athletes, particularly in women and is of importance as it may overlap with arrhythmogenic right ventricular cardiomyopathy (ARVC) [15]. A helpful discriminator is the presence of ST segment elevation in association with anterior T wave inversion, which is common in physiological adaptation, in contrast to the isoelectric or depressed ST segments seen in ARVC.

\section{Abnormal ECG findings in athletes (tab. 2)}

\section{T wave inversion}

Although normal in adolescent and black athletes, anterior T wave inversion beyond V2 warrants investigation in all other athlete groups. The significance of $\mathrm{T}$ wave inversion in the inferior leads is unknown in black athletes, but there is general agreement that $\mathrm{T}$ wave inversion in the inferior and/or lateral leads requires assessment in all athletes. $T$ wave inversion in III, aVR and V1, however, are normal findings in all athletes [13]. 


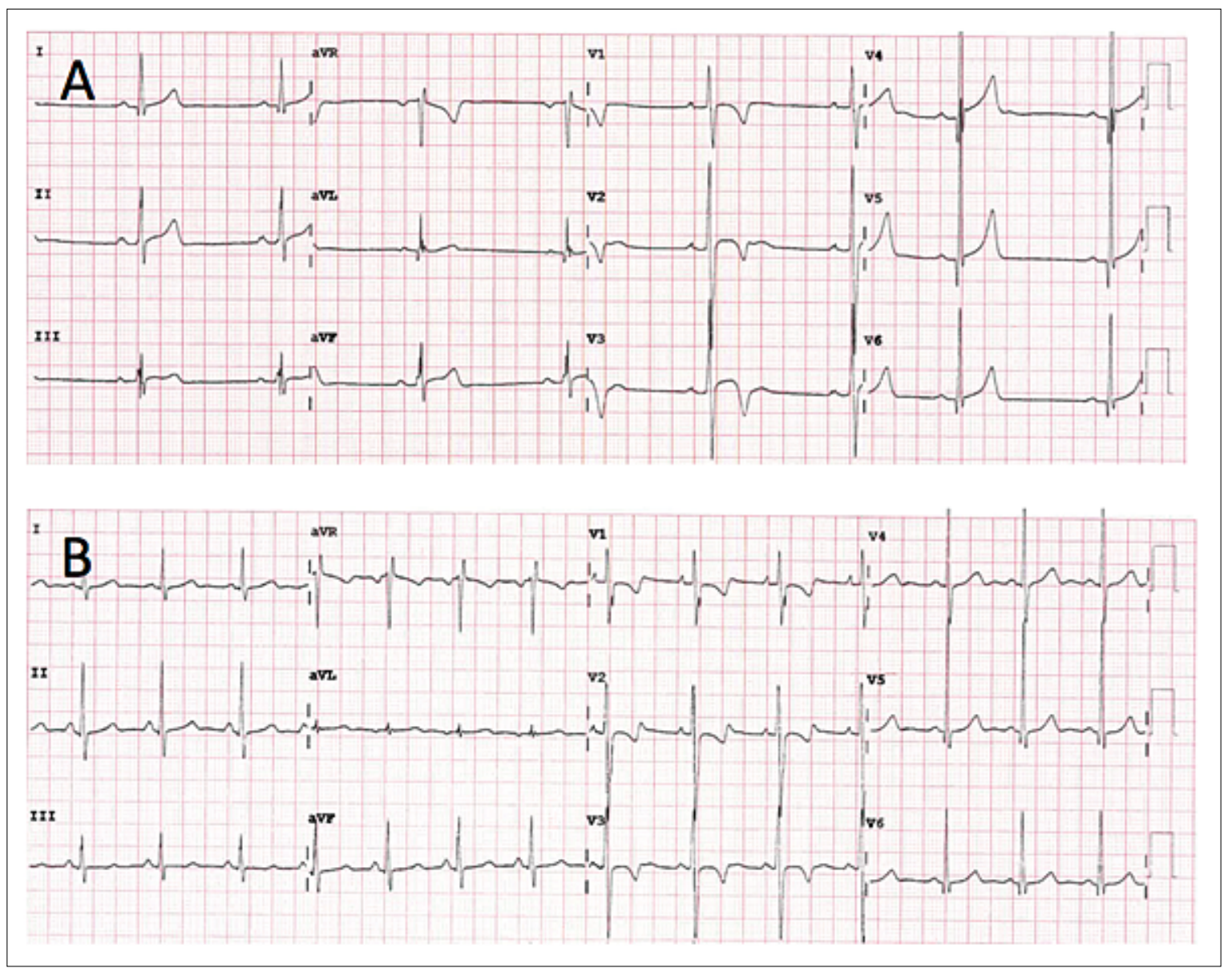

Figure 1: (A) Anterior T wave inversion preceded by $\mathrm{J}$ point elevation in an asymptomatic 18 -year-old black footballer. This is a normal repolarisation pattern in black athletes. (B) Anterior T wave inversion in a 15 -year-old female $800 \mathrm{~m}$ runner. This ECG is consistent with the juvenile pattern and should be repeated in 12 months to ensure resolution.

\section{Pathological Q waves, left bundle-branch block} and ST depression

Pathological $\mathrm{Q}$ waves $(\mathrm{Q} / \mathrm{R}>0.25$ or $\geq 40 \mathrm{~ms}$ in duration in two or more leads excluding III and aVR), ST segment depression $(\geq 0.5 \mathrm{~mm}$ in depth in two or more contiguous leads) and left bundle-branch block (LBBB) are not features of athletic training, yet common in patients with cardiac pathology [2].

\section{Pre-excitation and Brugada pattern}

Although a short PR interval in isolation in an asymptomatic athlete is acceptable, the Wolff-ParkinsonWhite ECG pattern always requires investigation, as does the type 1 Brugada pattern. Athletes with the type 2 Brugada ECG pattern should have a repeat ECG with leads V1 and V2 placed in the higher (second) intercostal space. The appearance of a type 1 Brugada pattern with this configuration warrants management as with all patients with Brugada syndrome. A type 2 pattern in association with syncope or in the context of a family history of SCD requires referral for expert opinion [2].

\section{Long QT}

Amongst athletes, a QT is considered prolonged if it measures $>470 \mathrm{~ms}$ in males and $>480 \mathrm{~ms}$ in females, once corrected for heart rate. Accurate measurement can only be made with use of the Bazett's formula when the heart rate lies between 60 and $90 \mathrm{bpm}$. Even with these values, the positive predictive value for long QT syndrome is below 7\% in asymptomatic patients without a family history. The presence of notched $\mathrm{T}$ waves in two or more leads or paradoxical prolongation of the QT during exercise in these athletes is highly suggestive of disease. Expert opinion should be sought in the case of doubt given the risk of SCD associated with sporting activity in long QT syndrome type 1 [2]. 
Table 2: Abnormal ECG findings in athletes (adapted from Sharma et al., 2017, International Recommendations for Electrocardiographic Interpretation in Athletes [2]).

\begin{tabular}{|c|c|}
\hline ECG Feature & Definition \\
\hline T wave inversion & $\begin{array}{l}>1 \mathrm{~mm} \text { in depth in } \geq 2 \text { contiguous leads (excluding } \\
\mathrm{III} \text { and } \mathrm{aVR} \text { ) }\end{array}$ \\
\hline Anterior: & $\begin{array}{l}\text { V2-V4 excluding; } \\
\text { - V2-V4 with preceding J point elevation and } \\
\text { convex ST elevation in Black athletes } \\
\text { - Athletes age }<16 \text { with T wave inversion in V1-V3; } \\
\text { and biphasic T waves in only V3 }\end{array}$ \\
\hline Lateral: & $\begin{array}{l}\text { I and } \mathrm{aVL}, \mathrm{V} 5 \text { and/or } \mathrm{V} 6 \text { (only one lead of } \mathrm{T} \text { wave } \\
\text { inversion required in } \mathrm{V} 5 \text { or } \mathrm{V} 6 \text { ) }\end{array}$ \\
\hline Anterolateral: & II and aVF, V5-V6 \\
\hline Inferior: & II and aVF \\
\hline ST depression & $\geq 0.5 \mathrm{~mm}$ in depth in $\geq 2$ contiguous leads \\
\hline Pathological Q waves & $\begin{array}{l}\mathrm{Q} / \mathrm{R} \text { ratio } \geq 0.25 \text { or } \geq 40 \mathrm{~ms} \text { in duration in } \geq 2 \text { leads } \\
\text { (excluding } \mathrm{III} \text { and } \mathrm{aVR} \text { ) }\end{array}$ \\
\hline $\begin{array}{l}\text { Complete left bundle branch } \\
\text { block }\end{array}$ & $\begin{array}{l}\text { QRS }>120 \text { ms, predominantly negative QRS complex } \\
\text { in lead V1 and upright notched or slurred } R \text { wave in } \\
\text { leads I and V6 }\end{array}$ \\
\hline $\begin{array}{l}\text { Profound Interventricular } \\
\text { conduction delay }\end{array}$ & QRS $\geq 140 \mathrm{~ms}$ \\
\hline Epsilon wave & $\begin{array}{l}\text { Small notch or positive deflection between the end } \\
\text { of the QRS and T wave in V1-V3 }\end{array}$ \\
\hline Ventricular pre-excitation & PR interval $<120 \mathrm{~ms}$ with delta wave $\&$ QRS $\geq 120 \mathrm{~ms}$ \\
\hline Prolonged QT & $\begin{array}{l}\text { QTc }>470 \text { ms males } \\
\text { QTc }>480 \mathrm{~ms} \text { females }\end{array}$ \\
\hline Type I Brugada pattern & $\begin{array}{l}\text { Coved pattern: ST segment elevation } \geq 2 \mathrm{~mm} \text { which } \\
\text { is downsloping followed by a negative symmetric } \\
\mathrm{T} \text { wave in } \mathrm{V} 1-\mathrm{V} 3\end{array}$ \\
\hline Profound sinus bradycardia & $<30$ beats/min or sinus pauses $\geq 3 \mathrm{~s}$ \\
\hline $\begin{array}{l}\text { Profound first degree atrioventri- } \\
\text { cular block }\end{array}$ & $\mathrm{PR} \geq 400 \mathrm{~ms}$ \\
\hline Mobitz II $2^{\circ}$ atrioventricular block & Systematic and intermittent non-conducted $\mathrm{P}$ waves \\
\hline $3^{\circ}$ atrioventricular block & $\begin{array}{l}\text { Complete atrioventricular dissociation, bradycardia } \\
\text { and often QRS }>120 \mathrm{~ms}\end{array}$ \\
\hline Atrial tachyarrhythmias & $\begin{array}{l}\text { Atrial fibrillation, atrial flutter, supra ventricular } \\
\text { tachycardia }\end{array}$ \\
\hline Premature ventricular complexes & $\geq 2$ in a 10 second trace \\
\hline Ventricular arrhythmias & $\begin{array}{l}\text { Couplets, triplets and non-sustained ventriclar } \\
\text { tachycardia }\end{array}$ \\
\hline
\end{tabular}

\section{Tachyarrhythmias}

Atrial arrhythmias including supraventricular tachycardia, atrial flutter and atrial fibrillation are all considered abnormal in an athlete. Equally, premature ventricular contractions occurring frequently ( $\geq 2$ per 10 second trace), couplets, triplets and non-sustained ventricular tachycardia are abnormal and warrant further investigation, with particular consideration of coronary artery disease as the underlying cause in athletes aged over 30 .

\section{ECG interpretation criteria in athletes}

\section{ESC and Seattle criteria}

Since it was first recognised that athletic conditioning produces an array of physiological ECG changes, there has been a prolific volume of research, resulting in a rapid evolution in our understanding of what is considered normal for an athlete.

A large study of 32652 Italian patients formed the basis for the first formal interpretation criteria produced by the European Society of Cardiology (ESC) in 2010 [16]. An expert consensus defined two groups of ECG changes. 'Group 1' changes, considered physiological variants not requiring further investigation, and 'Group 2' changes, rare in athletes ( $<5 \%)$ and considered unrelated to training, therefore warranting further evaluation. The recommendations recognised the importance of correctly interpreting ECG features that overlap with cardiomyopathies, such as $\mathrm{T}$ wave inversion and ST segment changes. However, within the young adolescent and black athlete cohort, in whom such changes are common, an unacceptably high number of false positives were present when these recommendations were applied. Furthermore, the ESC recommendations used very conservative cut-offs ( $>440$ $\mathrm{ms}$ in males and $>460 \mathrm{~ms}$ in females) for a prolonged QT interval in athletes, although it is recognised that athletes have a longer QT than the general population [17]. Consequently, an international consensus group developed the 'Seattle Criteria', which, amongst other minor modifications and additions, defined anterior $\mathrm{T}$ wave inversion (V1-V4) with preceding dome-shaped ST elevation, occurring in isolation, specifically in black athletes, as normal and redefined the upper limits for QT ( $>470 \mathrm{~ms}$ in males and $>480 \mathrm{~ms}$ in females) [18]. This application reduced false positive rates from 17 to $4.2 \%$ in a cohort of 1078 Australian athletes [19].

\section{Refined criteria}

In 2014 'refined criteria' were devised which resulted in a significant reduction in the number of false positive ECGs, while maintaining sensitivity [24]. The criteria reclassified some Group 2 (abnormal) ESC parameters into a third 'borderline' group that in isolation can be considered normal but, when coexisting with other borderline or Group 2 criteria, warrant further tests (tab. 3). Specifically, the borderline changes included (1) left atrial enlargement, (2) right atrial enlargement, (3) left axis deviation, (4) right axis deviation, (5) SokolowLyon voltage criteria for right ventricular hypertrophy and (6) T wave inversion up to V4 in black athletes (when preceded by convex ST segment elevation). The inclusion of right ventricular hypertrophy in the borderline group arose from a study examining a large group of athletes showing that voltage criteria for right ventricular hypertrophy was present in up to $11 \%$ of athletes. No athlete had any echocardiographic or MRI evidence of cardiac disease. The study also assessed pa- 
Table 3: Borderline ECG findings in athletes (adapted from Sharma et al., 2017,

International Recommendations for Electrocardiographic Interpretation in Athletes [2]).

\begin{tabular}{ll}
\hline ECG Feature & Definition \\
\hline Left axis deviation & $-30^{\circ}$ to $+90^{\circ}$ \\
\hline Left atrial enlargement & $\begin{array}{l}\mathrm{P} \text { wave duration } \geq 120 \mathrm{~ms} \text { in } \mathrm{I} / \mathrm{Il} \text { with negative portion P wave } \\
\geq 1 \mathrm{~mm} \text { in amplitude and } \geq 40 \mathrm{~ms} \text { in duration in } \mathrm{V} 1\end{array}$ \\
\hline Right axis deviation & $>120^{\circ}$ \\
\hline Complete RBBB & $\begin{array}{r}\text { rSR' pattern in lead V1 and an S wave wider than } \mathrm{R} \text { wave in } \\
\text { lead } \mathrm{V} 6 \text { with QRS duration } \geq 120 \mathrm{~ms}\end{array}$ \\
\hline
\end{tabular}

Sanjay Sharma, BSc, MD

FRCP, FESC

Cardiology Clinical and

Academic group

St George's University

of London

Cranmer Terrace

UK-London SW17 ORE

Sasharma[at]sgul.ac.uk showed that all individuals with those pathologies exhibit other pathological ECG changes in addition to right ventricular hypertrophy [21]. The most recent international recommendations for the interpretation of the ECG in athletes considers right ventricular hypertrophy a physiological feature of adaptation requiring no further consideration.

Recent data from Malhotra et al. studying $\mathrm{T}$ wave inversion in 16646 white 18 - to 35 -year-olds $(20 \%$ athletes), reported a $2.3 \%$ prevalence of anterior T wave inversion (defined as $\mathrm{T}$ wave inversion in $\geq 2$ contiguous leads V1-V4), being more common in athletes (3.5 vs $2.0 \%$, respectively; $\mathrm{p}<0.0001$ ). No individual with anterior $\mathrm{T}$ wave inversion was found to have a cardiomyopathy despite extensive investigation. However, anterior $\mathrm{T}$ wave inversion beyond $\mathrm{V} 2$ was very rare $(1.2 \%$ in females and $0.2 \%$ in males). Overall, the recommendations conclude that the presence of anterior $\mathrm{T}$ wave inversion up to $\mathrm{V} 2$ in an asymptomatic white individual (athlete or not) who has no family history of SCD or inherited cardiac conditions, should be considered normal [16].

\section{International recommendations}

In February 2017, a global consensus group consisting of the most prolific sports cardiology physicians and cardiologists, published 'The International Recommendations for the Interpretation of the ECG in the Athlete', a concise and comprehensive document based on the latest research. These recommendations clarify some of the existing parameters, such as the limit be- tients with ARVC and pulmonary hypertension and low which sinus bradycardia is considered abnormal ( $<30 \mathrm{bpm}$ ) and the maximum normal upper limit for first-degree heart block (PR interval up to $400 \mathrm{~ms}$ ). They also extend the breadth and depth of the guidance for interpreting common findings, particularly $\mathrm{T}$ wave inversion, which is one of the most common findings in serious inherited conditions including; ARVC and hypertrophic cardiomyopathy [2]. The application of these criteria to almost 5000 predominantly white athletes showed a positive ECG rate of $3 \%$ and a $66 \%$ reduction in the number of athletes who would require echocardiography after an ECG compared with the original 2010 ESC recommendations [22].

\section{Conclusion}

An athlete's ECG should be interpreted in accordance with the latest recommendations that embody the most recent evidence and consensus opinions. Correct interpretation of the athletes' ECG requires acknowledgement of an individual's characteristics, including age, sex, ethnicity, sporting discipline and level of conditioning. When an athlete's ECG is defined as abnormal, measures must be taken for prompt and comprehensive evaluation. Discontinuation of training and competing should be considered until results are available. The subsequent diagnosis of a potentially hereditary condition will necessitate family cascade screening as appropriate.

It must be acknowledged that some conditions predisposing to SCD do not manifest on the resting ECG, for example, coronary artery anomalies.

Continued scientific research is crucial to further improve our ability to differentiate cardiac pathology from physiological adaptation.

\section{Disclosure statement}

No financial support and no other potential conflict of interest relevant to this article was reported.

\section{References}

The full list of references is included in the online version of the article at www.cardiovascmed.ch 